\title{
Guia de Gestão Autônoma de Medicamentos como dispositivo na formação médica
}

\author{
Carla Graziela Paes Ladeira, Lia Melero dos Anjos, Marcio Loyola de Araújo, Gabriela Pires da \\ Rosa, Marina Rodrigues Lemos, André Miranda de Oliveira
}

\section{Resumo}

Este trabalho relata a experiência de um grupo de estudos formado por pesquisadores e acadêmicos de medicina da Universidade Federal Fluminense no intuito de investigar as implicações na formação médica da cogestão nas práticas de saúde e da construção da autonomia. $\mathrm{O}$ grupo de estudos é resultado do desdobramento de uma pesquisa de doutorado em curso na mesma universidade, cujo projeto encontra-se em fase de autorização para intervenção no serviço público de saúde mental do município de Niterói, tendo como proposta a utilização do guia de Gestão Autônoma de Medicamentos (GAM) para problematização das práticas de uso de psicotrópicos, de construção dos processos terapêuticos e de reprodução da medicalização da saúde mental. O guia GAM, de origem canadense, foi adequado à realidade brasileira por pesquisadores e usuários de saúde mental e é formado por pequenos textos e perguntas relacionadas às experiências dos usuários com psicotrópicos. Através de sua leitura conjunta em grupos terapêuticos, funciona como um dispositivo que problematiza questões relativas às formas de utilização de medicamentos psiquiátricos, instigando a maior participação dos usuários no tratamento, favorecendo o questionamento da hegemonia do saber médico expressa no processo de medicalização e possibilitando a construção cogestiva de novas formas de cuidado e de produção do conhecimento. Este estudo tem como objetivos: promover a preparação metodológica, bibliográfica e sensível de pesquisadores e graduandos de medicina para intervenção no serviço público de saúde mental de Niterói; provocar a implicação de pesquisadores, usuários e trabalhadores na proposição de terapêuticas mais participativas e produtoras de autonomia; avaliar o impacto desse processo na formação médica. Através de reuniões semanais do grupo de estudos, foram produzidos debates, visitas a serviços de saúde mental e articulação com a equipe do ambulatório de Pendotiba (integrante da rede de saúde mental de Niterói/RJ), com o intuito de construir uma proposta de intervenção no mesmo, a ser iniciada em setembro de 2016. Dois alunos de graduação em Medicina e um pesquisador do grupo de estudos participarão da intervenção com usuários e trabalhadores no ambulatório citado e os demais integrantes atuarão como supervisores através do compartilhamento semanal da experiência vivida. Ao final, serão avaliados os impactos que a intervenção, o alinhamento teórico e a partilha de experiências terão na formação médica dos alunos participantes. Além de fomentar a busca por práticas de saúde cogestivas que estimulem a autonomia do usuário e do trabalhador, a participação no projeto tem permitido que alunos e pesquisadores atentem-se à forma como o conhecimento médico é produzido, muitas vezes excluindo, deste processo, o usuário dos serviços; estimulado a produção de autonomia e uma forma de produção de saberes que inclui o conhecimento do usuário no cuidado em saúde e fomentado o questionamento da medicalização do campo da saúde. Encontramos no guia GAM uma abordagem incomum à prática médica habitual, oposta à medicalização e com a proposta de substituição do vínculo disciplinar e vertical pela relação cogestiva, a qual propicia a construção da autonomia do usuário de saúde e o cuidado com o outro.

Descritores: Gestão Autônoma de Medicamentos; Formação médica; Cogestão 